Is Trusting Others Related to Better Health?

An Investigation of Older Adults across Six Non-Western Countries

\author{
Derwin King Chung Chan ${ }^{1,2}$ \\ Takeshi Hamamura ${ }^{2}$ \\ Liman Man Wai $\mathrm{Li}^{3}$ \\ Xin Zhang ${ }^{4}$ \\ ${ }^{1}$ University of Hong Kong, Hong Kong \\ ${ }^{2}$ Curtin University, Australia \\ ${ }^{3}$ Sun Yat-sen University \\ ${ }^{4}$ Peking University
}




\begin{abstract}
Generalized trust reflects whether individuals extend their trust to others in general and is important to health and well-being. This study examined the predictive effect of generalized trust on health, happiness, life satisfaction, health behaviors, and illnesses among older adults residing in six nonWestern countries. We utilized a recent multinational dataset collected by the World Health Organization that included measures of generalized trust, health, happiness, life satisfaction, health behaviors (physical activity, diet), health-compromising behaviors (sedentary behavior, cigarette and alcohol consumption), and illnesses (e.g., angina, arthritis, asthma, cataracts, depression, hypertension, and lung disease) among adults aged 50 and older. The sample comprised a total of 35,329 adults (mean age $=63.54)$ from China, Ghana, India, Mexico, South Africa, and Russia. An index of the development of these countries was also entered into the analyses. Hierarchical multiple regression showed that generalized trust was a significant and positive predictor of selfrated health, happiness, life-satisfaction, and quality of life, and a negative predictor of illness (i.e., angina, arthritis, asthma, cataracts, diabetes, depression, hypertension, and stroke) and sedentary behavior. The associations were stronger for countries with a higher Human Development Index (HDI) than those with a low HDI. While the findings from this first multinational investigation of non-Western developing countries are consistent with the results of previous studies in Western developed countries, they also underscore their cross-societal variability.
\end{abstract}


Is Trusting Others Related to Better Health?

An Investigation of Older Adults across Six Non-Western Countries

Trust is a belief that other individuals' actions will be beneficial to oneself (Gilson, 2003) and the associated willingness to accept the vulnerability that such an expectation may pertain (Balliet \& Van Lange, 2013). Trust has been an important concept to psychological research for decades. A number of prominent psychology theories, such as Erikson's theory of social development (Erikson, 1963), Bowlby's attachment theory (Bowlby, 1980), and Rogers's humanistic psychology (Rogers, 1951), view trust as an element fundamental to psychological wellbeing and effective psychological functioning.

Individuals' trust of others in general, commonly known as generalized trust, is distinct from trust of someone well-known, because the absence of intimate personal knowledge makes oneself vulnerable to others' potentially malicious actions (Nannestad, 2008; Yamagishi \& Yamagishi, 1994). An increasing volume of literature suggests generalized trust is an important factor for health and well-being (e.g., Barefoot et al., 1998; Poortinga, 2006). Arguably, generalized trust is particularly important among older adults as they become more reliant on others in maintaining physical health (Cagney \& Wen, 2008). The current research examined the relationship between generalized trust and health and well-being by utilizing the unique dataset made available by the World Health Organization (WHO) that covers issues pertaining to adult health and aging with participants recruited from China, Ghana, India, Mexico, Russia, and South Africa.

\section{Trust and Health}

In close interpersonal relationships, trust facilitates a secure social environment by reducing feelings of insecurity, worry, or anxiety, which are risk factors of health (Schneider et al., 2011). For example, a longitudinal study found that trust (in a romantic relationship) was a positive predictor of self-rated health, while anxiety and depression mediated this relationship (Schneider et al., 2011). This finding also resonates with a large body of research that has identified negative 
interpersonal orientation (e.g., cynicism, suspiciousness, hostility) as risk factors of health (e.g., Everson et al., 1997; Houston et al., 1991; Smith et al., 1988).

In addition to psychological health, generalized trust has been proposed to be a positive correlate of physical health (e.g., Barefoot et al., 1998; Heliwell \& Putnam, 2004; Kim, Subramanian, \& Kawachi, 2008). An analysis of data from a large-scale survey in the United Kingdom found that individuals who expressed generalized trust of others, answering yes to the item "Generally speaking, would you say that most people can be trusted or that you need to be very careful in dealing with people?", were about $30 \%$ less likely to report poor health compared with individuals who answered no to the same question (Poortinga, 2006). Consistent findings regarding the relationship between generalized trust and self-rated physical (as well as psychological) health have been observed in a population study in Sweden (Lindström, 2004; Mohseni \& Lindström, 2007). The relationship between generalized trust and health has also been evident in a recent study using data from the World Value Survey (wave six) involving 50 societies (Hamamura, Li, \& Chan, 2016). It was found that individuals who believed that "most people can be trusted", as compared to those who believed that "[we] need to be very careful", reported better psychological health (i.e., happiness, and life satisfaction), as well as self-rated physical health (Hamamura, Li, \& Chan, 2016). The systematic review by Kim, Subramanian, and Kawachi, (2008) has identified a notable number of studies that measured social trust/ mistrust (to others) and a wide range of physical health indices. They found that trusting others (i.e., social cohesion, or as an indicator of social capital) is linked to self-rated health $(\mathrm{k}=32)$, all-cause mortality or life expectancy $(\mathrm{k}=15)$, cardiovascular disease $(\mathrm{k}=7)$, obesity and diabetes $(\mathrm{k}=4)$, and infectious disease $(\mathrm{k}=3)$. In sum, research has provided solid evidence that generalized trust is a positive correlate of psychological and physical health, and a negative correlate of the risk of diseases. It is important to note that prior research largely relied on self-rated health, instead of objectively measured diseases, as the health outcome variable. 
Why is generalized trust correlated with health? One agreement among theorists is that generalized trust is a crucial element of social connectedness (e.g., Delhey et al., 2011; Heliwell \& Putnam, 2004). Social connectedness, in turn, benefits health through enhancement of social support and social resources that are closely linked to individuals' perception of stress, psychological status, and more importantly, health behaviors (Cohen, 2004; Lindström, 2008). To examine the tenets regarding the relationship between generalized trust and health behaviors, Nieminen and coworkers (2013) analyzed the a national health survey in Finland to examine if generalized trust is linked to smoking, alcohol use, physical activity, diet, and sleep among 8028 adults aged 30 or above. It was found that individuals reported higher level of generalized trust were more likely to be non-smokers, non-excessive drinkers, consume more vegetables in an average week, do more leisure-time physical activity, and have adequate sleep (i.e., 7 hours or more). Consistent patterns of results have been revealed in the line of research by Lindström and colleagues (see Lindström, 2008 for a review) who found in the national health survey of Sweden that generalized trust, as one of the significant indicators of social capital, was associated negatively with alcohol consumption (Lindström, 2005) and cigarette smoking (Lindström, Moghaddassi, Bolin, Lindgren, \& Merlo, 2003), and positively with physical activity (Lindström, Moghaddassi, \& Merlo, 2003). The overall findings appear to support the view that generalized trust is not only predictive to psychological health, but also to physical health and health-related behaviors. However, each of these studies only represented a single country from Europe, and they did not have a specific focus on older adults who typically have more health-related concerns due to aging. For older adults, generalized trust is believed to be especially important because: (1) older adults come to prioritize emotionally meaningful goals, including social connectedness, with ageing (Li \& Fung, 2013) and (2) older adults come to become more dependent on their social connections in maintaining health (e.g., due to reduced mobility) ${ }^{1}$ (Cagney \& Wen, 2008). Consistent with this

\footnotetext{
${ }^{1}$ Currently it is not known whether the association between generalized trust and health is stronger among older than younger adults. Although this pattern was found in a study that examined life
} 
rationale, Barefoot et al. (1998) reported that within an elderly sample (average age $=67$ years old), scores on Rotter's Interpersonal Trust Scale (which includes items such as "In dealing with strangers one is better off to be cautious until they have provided evidence that they are trustworthy") were predictive of self-rated health measured eight and 14 years later. Intriguingly, the same study also found that the participants who had a higher level of interpersonal trust at the baseline had a significantly higher likelihood of surviving in the follow-ups compared with those with a lower level of trust (Barefoot et al., 1998; see also Nummela et al., 2009; 2012).

Thus far, the positive association between generalized trust and health among older adults was reported in only a small number of studies from Western countries. This is a limitation because some research suggests that generalized trust may exert a stronger effect (e.g., its effect in predicting perceived social standing) in developed than developing societies (Hamamura, 2011). This account can be tested by analyzing the role of societal development in moderating the association between generalized trust and the benefit it confers, as effectiveness of public institutions is one of the hallmarks of society development (Hamamura, 2011). In relation to health, Hamamura and colleagues (2016) preliminarily showed that human development index (HDI) of the countries moderated the predictive values of generalized trust on self-rated health and happiness. It might be due to the fact that in developing countries, individuals' health status is more dependent on the environmental (e.g., hygiene) and external factors (e.g., accessibility of medical resources and public health promotion), in relative to social factors such as generalized trust (Jamison et al., 2006). Also, although generalized trust may benefit the efficiency of health services by reducing burden of performance inspection and transaction costs associated with uncertainty in working relationship, the down side of trust is that it may increase the risks of exploitation, corruption, overuse of power, and unequal distribution of resources (Gilson, 2003), which are more commonly seen in developing countries (i.e., low HDI) than in developed countries (i.e., high HDI).

satisfaction (Poulin \& Hasse, 2013), to the best of our knowledge, whether this pattern extends to health is still an open question. 
As these risks are likely to impair the efficiency of health services (Gilson, 2003), it is reasonable to observe that the effect of generalized trust on health is more salient in countries with high HDI than countries with low HDI (Hamamura et al., 2016). However, the study of Hamamura and colleagues (2016) only examined subjective self-rated health, rather than report of diseases, health behaviors, and health compromising behaviors, and the focus was general population instead of older adults. It is, therefore, important that research examined if generalized trust links to a broader range of health indicator among older adults, and investigate whether the links varies across societies in terms of social development of the countries.

\section{Current Investigation}

The current research presents a conservative test of this possibility in examining the effects associated with development among samples recruited from non-Western countries (vs. comparisons between Western industrialized countries and non-Western developing countries). The present study incorporated multiple indices of health, chronic illnesses, health behaviors and healthcompromising behaviors, and psychological well-being. Hence, this research complements extant literature in the field based on the findings obtained from self-rated psychological and physical health (Barefoot et al., 1998; Hamamura et al., 2016; Nummela et al., 2008; Nummela et al., 2012), and health-related behaviors (Cohen, 2004; Lindström, 2008). Consistent with the literature regarding the positive association between generalized trust and health, we hypothesized that generalized trust would positively predict health behaviors (i.e., physical activity and a healthy diet) and psychological well-being (i.e., happiness, life satisfaction, and quality of life), and negatively predict health-compromising behaviors (i.e., drinking and smoking) and illnesses history (i.e., angina, arthritis, asthma, cataracts, diabetes, depression, hypertension, chronic lung disease, and stroke). These outcome variables have been regarded as important factors or indicator of health (Lim, Vos, \& Flaxman, 2013; World Health Organization, 2008, 2015). Also, based on the findings of Hamamura and coworkers (2016) that the predictive value of generalized trust on health would be stronger in developed countries than in developing countries, we hypothesized that the 
relationship between generalized trust and these health indices would be moderated by HDI.

\section{Method}

\section{Participants}

The WHO maintains a dataset comprising of issues pertaining to adult health and aging (http://www.who.int/healthinfo/sage/en) with participants recruited from China, Ghana, India, Mexico, Russia, and South Africa. The entire dataset consists of a large number of participants aged 50 years and older plus a smaller comparison sample of those aged 18 to 49 years old. In order to conduct analyses that focus on older adults, the analyses below excluded participants younger than 49 years old. Table 1 summarizes the descriptive statistics of the samples.

\section{Measures}

Generalized Trust. The participants responded to the item "Generally speaking, would you say that most people can be trusted or that you can't be too careful in dealing with people?" $(0=$ Can't be too careful; $1=$ Can be trusted). This dichotomous item is one of the most commonly used measures of generalized trust (Nannestad, 2008). Although reliability is generally an issue for a single-item measure, available evidence indicates that this item is known to yield valid and reliable responses (see Nannestad, 2008; Poortinga, 2006).

Self-Rated Health. The participants offered a subjective rating of their overall health status on a single-item measure of self-rated health that is widely used in health research: "In general, how would you rate your health today?" (1= Very good to $5=$ Very bad). We reversed the scoring so that higher scores indicated better health conditions. Numerous studies have demonstrated that selfrated health is a valid and reliable indicator of one's overall health status (Chan, Zhang, Fung, \& Hagger, 2016), predicting mortality (Benyamini \& Idler, 1999; Idler \& Angel, 1990; Idler \& Benyamini, 1997), disability (Idler \& Kasl, 1995; Kaplan, Strawbridge, Camacho, \& Cohen, 1993), and morbidity (Ferraro, Farmer, \& Wybraniec, 1997). 
Happiness. The participants responded to the item "Taking all things together, how would you say you are these days? Are you..." with a 4-point Likert scale (1= Unhappy to $4=$ Very happy). This is also a widely used single-item measure of happiness (Andrews \& Robinson, 1991).

Life Satisfaction. The participants answered the item "Taking all things together, how satisfied are you with your life as a whole these days?" to report their life satisfaction $(1=$ Very dissatisfied to 5 = Very satisfied). This item has been widely adopted, including in major surveys such as the World Values Survey.

Quality of Life. Eight items from the EUROHIS-QOL index (Schmit, Mühlan, \& Power, 2005) assessed the participants' satisfaction in psychological, physical, social, and environmental domains, with the overall score indicating the participants' quality of life. Sample items included "How satisfied are you with your health?" and "How satisfied are you with the conditions of your living condition?". The responses were indicated on a 5 -point scale $(1=$ Very dissatisfied to $5=$ Very satisfied). The responses to the eight items were aggregated to a single index of quality of life with acceptable internal consistency (China: $\alpha=.87$; Mexico: $\alpha=.81$; Russia: $\alpha=.82$; India: $\alpha=$ .85; South Africa: $\alpha=.84$; Ghana: $\alpha=.86$ ).

Illnesses. The participants reported whether they had ever ${ }^{2}$ been diagnosed with the following nine conditions: (1) angina, (2) arthritis, (3) asthma, (4) cataracts, (5) diabetes, (6) depression, (7) hypertension, (8) chronic lung disease, and (9) stroke ( $0=$ No; $1=$ Yes $)$.

Health Behaviors. Diet. The participants responded to two items about how many servings of (1) fruits and (2) vegetables they eat on a typical day. The sum of these two items indicated their daily consumption of fruits and vegetables.

Physical Activity. Items from the International Physical Activity Questionnaire (IPAQ; Craig et al., 2003) assessed whether the participants (a) do vigorous or moderate intensity physical activity at work and how much time they do such work (number of days in a typical week and the amount of time on a typical day), (b) walk or cycle to get to and from places and the amount of time

\footnotetext{
${ }^{2}$ Last five years for cataracts.
} 
spent on those activities, and (c) do any vigorous or moderate intensity leisure activities and the amount of time spent on those activities. The responses were converted to minutes and were multiplied by the weight of the activities (i.e., the amount of time $\mathrm{x} 2$ for vigorous activities and $\mathrm{x} 1$ for other (i.e., moderate to light intensity) activities) to reflect relative energy consumption (Jette, Sidney, \& Blümchen, 1990). The sum of these weighted scores reflected the daily volume of physical activity.

Health-compromising Behaviors. Drinking. The participants indicated for the last 12 months (a) how frequently they drank at least one alcoholic drink $(0=$ No days; $1=$ Less than once a month; $2=$ One to three days per month; $3=$ One to four days per week; $4=$ Five or more days per week) and (b) how many drinks they had on the days when alcohol was consumed. The responses to these two items were multiplied to indicate the participants' alcohol consumption.

Smoking. The participants indicated (a) how long they have been smoking and (b) how many different types of products (e.g., manufactured cigarettes, cigars) they smoked each day. The responses to these two items were multiplied to indicate the participants' consumption of smoking products.

Sedentary Behavior. The participants responded to another question from the IPAQ (Craig et al., 2003): "How much time do you usually spend sitting or reclining on a typical day?". The responses were converted to minutes to indicate daily sedentary time.

Development. The countries' social development was indexed by the Human Development Index (HDI). The HDI is a composite of three demographics: life expectancy at birth, years of schooling, and gross national income (GNI) per capita (United Nations Development Program: http://hdr.undp.org/en/content/human-development-index-hdi). The HDI ranges from 0 to 1, with 1 indicating the highest social development. The countries' scores for the HDI were used in the analyses reported below.

\section{Data Analyses}


We conducted linear regression analyses for continuous dependent variables (i.e., self-rated health, happiness, life satisfaction, quality of life, physical activity, diet, drinking, smoking, and sedentary behavior) and logistic regression analyses for dichotomous dependent variables (i.e., angina, arthritis, asthma, cataracts, diabetes, depression, hypertension, chronic lung disease, and stroke) ${ }^{3}$ All analyses included the participants' age, gender $($ Male $=1$; Female $=2)$, and household income (income quintile from $1=$ Low income to $5=$ High income) to conduct analyses that controlled for the effects of these demographic variables.

For each dependent variable, the first step of the analysis entered the participants' age, gender, and income along with the HDI. The second step added generalized trust and the third step added the interaction term between generalized trust and the HDI, computed by multiplying generalized trust and the HDI, with the HDI centered for the entire sample (Keith, 2005, pp. 129160). A significant interaction indicated that the effect of generalized trust on a particular dependent variable was not uniform across the countries' HDI. To probe the moderation effect, we subsequently estimated the simple main effect of generalized trust at a high level of the HDI (1 SD above the mean of the HDI) and then at a low level of the HDI (1 SD below the mean of the HDI) (Aiken \& West, 1991).

\section{Results}

\section{Does Generalized Trust Predict Health and Well-being?}

Generalized trust was significantly associated with 14 of the 18 dependent variables (exceptions were lung disease, physical activity, drinking, and smoking) (see Table 2). These significant associations indicated that generalized trust was predictive of better health and wellbeing; that is, generalized trust was related to better self-rated health, happiness, life satisfaction, and quality of life. It was also negatively associated with angina, arthritis, asthma, cataracts,

\footnotetext{
${ }^{3}$ Although the dataset has a nested structure, the use of multilevel modeling (e.g., hierarchical linear modeling) is not appropriate because a small sample size at the country level $(n=6)$ would lead to an underestimation of the associated standard errors, implicating the risk of false positives in identifying group differences (see Maas \& Hox, 2005).
} 
diabetes, depression, hypertension, and stroke. Additionally, generalized trust was a positive predictor of diet and a negative predictor of sedentary behavior.

\section{Does the HDI Moderate the Relationship between Generalized Trust and Health?}

We focused on 14 indices for which trust was a significant predictor and examined whether the effect of trust was stronger among participants in more-developed countries. Of the 14 indices, in 12 indices the countries' development (HDI) significantly moderated the effect of generalized trust (see Table 2). Specifically, the HDI moderated the relationship between generalized trust and self-rated health, happiness, life-satisfaction, quality of life, angina, arthritis, asthma, cataracts, depression, hypertension, diet, and sedentary behavior (exceptions were stroke and diabetes). Follow-up analyses, as mentioned above, were conducted on these 12 indices (see Table 3). In all of these indices, the effects associated with trust were stronger with higher level of the HDI. Specifically, whereas generalized trust was predictive of better self-rated health, happiness, lifesatisfaction, and quality of life, a lower likelihood of angina, arthritis, asthma, cataracts, depression, and hypertension, and a higher intake of fruits and vegetables, and less time spent on sedentary activities; these associations were more pronounced at a higher level of the HDI. In sum, the findings indicated that the positive association with generalized trust on most health-related outcomes was stronger in countries with a relatively higher level of human development.

\section{Discussion}

This research examined the association between generalized trust and indices of health, well-being, and health behaviors among older adults residing in six non-Western countries. The findings converged in confirming the robust positive association between generalized trust and health. Generalized trust predicted greater self-rated health and well-being (i.e., happiness, lifesatisfaction, and quality of life), a lower likelihood of having a history with a number of illnesses (i.e., angina, arthritis, asthma, cataracts, diabetes, depression, hypertension, and stroke), and more health behaviors (i.e., a greater intake of fruits and vegetables and less sedentary activities). The findings obtained from the analyses of multiple indices of health and well-being of older adults 
from six different countries with various level of human development extend prior work that largely focused on self-rated health, using dataset from a single country primarily from developed Western nations, and representative to adult.

Despite the consistency in the pattern across a range of indices, it should be noted that the effect size of these significant associations was not very large. Although generalized trust was significantly associated with 14 of the 18 indices examined, for three of the 14 indices (quality of life, depression, and intake of vegetables and fruits), the effect size was "small" ( $\Delta \mathrm{R}^{2}$ between .01 and .09), and for the remaining 11 indices, the effect size did not reach the conventional threshold for a small effect size $\left(\Delta \mathrm{R}^{2}=.01\right)($ Cohen, 1992). For instance, in predicting self-rated health, the amount of variance associated with generalized trust was $\Delta \mathrm{R}^{2}=.004$, which is smaller than the effect size reported in prior research-Barefoot et al. (1998) found a small effect size ( $r=.26$ or $\mathrm{R}^{2}$ $=.068$ ) between trust and self-rated health. One possibility for this discrepancy is the measure of generalized trust used. Unlike the single-item measure used in the current research, and many other studies in this area (Nannestad, 2008), Barefoot et al. (1998) used a measure consisting of 25 items. Our analyses might have contained more noise in computing the effects associated with generalized trust. This issue deserves further consideration in the field, especially because the item incorporated in the current research is the most frequently analyzed measure of generalized trust in the literature (Nannestad, 2008).

An alternative interpretation of the smaller effect size of generalized trust found in the current research, of course, stems from sampling differences. Unlike Barefoot et al. (1998) who examined American participants or Nummela and colleagues $(2009,2012)$ who examined Finnish participants, the current research examined participants from six non-Western developing nations. As such the observed smaller effect size may suggest the possible role of the countries' development differences in moderating the effect associated with generalized trust. Some support for this proposition was obtained in the current research. In most of the indices analyzed, the effect of generalized trust differed across the countries as a function of the level of human development, 
and in all cases, this variation reflected the stronger effect of generalized trust in relatively moredeveloped countries. These findings are consistent with the results of Hamamura and colleague (2016) who analyzed the data of 50 societies from the World Value Survey, and also the proposition from recent literature that psychological benefits associated with generalized trust are more salient in developed societies compared with developing countries (Hamamura, 2011). On the other hand, the findings might imply that development, and economic growth of a country could plausibly make generalized trust a more important correlate of older adults' health status. It would be interesting for future study to examine this speculation by monitoring the association between generalized trust and health along with the development of a country. In sum, the current analyses provide some preliminary evidence suggesting that health benefits reported among trusting older adults may be relatively more pronounced in developed countries.

There were two findings that deviated from the account above. First, in four of the eighteen indices examined (lung disease, physical activity, drinking, and smoking), their associations with generalized trust were not significant. For lung disease, the non-significant might be due to the influence of environmental (e.g., pollution) and occupational (e.g., dust, chemicals) factors of this type of disease (Mitchell \& Popham, 2008). On the other hand, the non-significant findings in relation to physical activity, drinking, and smoking were somewhat against the findings of previous studies from Europe (Lindström, 2005, 2008; Lindström et al., 2003; Nieminen et al., 2013). Apart from sedentary behavior and (healthy) dieting that were associated with generalized trust according to our hypothesis, our findings provided a view different from the current literature about the positive role of generalized trust on the lifestyle or behavioral factors related to health (Lindström, 2008; Nieminen et al., 2013). One possible reason is that certain health behaviors or health compromising behaviors are heavily influenced by the acceptance or support of the behaviors in certain cultures, and so the relative impact of generalized trust on these behaviors that we observed in the six non-western countries might somewhat be different from that of previous studies conducted in Europe (Lindström, 2008; Nieminen et al., 2013). For example, cross-cultural 
differences between some European and Asian countries have been reported in terms of the beliefs and motivational factors of physical activity (Hagger, Chatzisarantis, et al., 2007) and binge drinking (Hagger et al., 2012). Such discrepancies might be related to the our hypothesized moderating effect of human development index because the non-Western countries we included in this study, in general, have a HDI lower than European countries, and this might undermine the effect of generalized trust on health behaviors. However, such speculation affords further investigation for a cross-cultural comparison between Western and non-Western countries on the link between generalized trust and healthy lifestyle. Second, in two of the fourteen indices examined (stroke and diabetes), the association with generalized trust was not moderated by HDI. The unexpected results for stroke and diabetes may be due to the complexity of the etiology of diseases or behaviors when taking all the environmental factors, genetic factors, and personal (e.g., age) and cultural factors into account (Mitchell \& Popham, 2008). The moderating effect of HDI might have been influenced by these factors. Indeed, in general the findings support our hypothesis regarding the moderating effect of HDI on the relationship between generalized trust and health, which illustrated that potential health benefit of generalized trust might be stronger in more developed countries than less developed countries (Hamamura et al., 2016). These findings are in agreement with the proposition of Gilson (2003) who argued that trust might undermine efficiency or performance or health services as it might level the risk of exploitation, corruption, overuse of power, and unequal distribution of resources, that present more often in less developed countries. Therefore, generalized trust, due to its potential benefits on enhancing the efficiency of the services and support to public health, appears to be a positive correlate of health, well-being, and healthy lifestyle in the older adults of the six non-Western countries, however, the effect of generalized trust on health is less salient on countries with lower HDI.

Limitations in the current findings should also be noted. First, the cross-sectional and correlational design of the study restricted the level of evidence regarding the temporal and causal relationship between generalized trust and health. While an experimental study manipulating either 
generalized trust or health would face notable challenges in ethics and treatment efficacy, it is possible for a future study to longitudinally observe whether the natural variation of generalized trust is associated with a change of health status, or vice versa (Hagger, Chan, Protogerou, \& Chatzisarantis, 2016). Second, the self-reported measures of the study variables using a survey as the central medium of data collection could have been subjected to response bias due to social desirability, memory loss, and common method variance (e.g., consistency tendency; Chan, Ivarsson, Stenling, Yang, Chatzisarantis, \& Hagger, 2015). Third, a retrospective assessment of illness history could not represent the participants' current illness status, which was not clinically and objectively reported by medical professionals, even though such an assessment has been commonly applied in large-scale national surveys (Chan, Zhang, Fung, \& Hagger, 2016). Adopting more objective measures of health (e.g., analyses of medical records or blood tests) and behavioral outcomes (e.g., an accelerometer for assessing physical activity and sedentary behavior) would be highly valuable for future research. Finally, although this research highlights the role of one societal characteristic, development, in influencing health benefits of generalized trust, the finding does not suggest against a role of other societal and cultural characteristics. In particular, one alternative possibility is that the reported pattern reflects societal differences in individualism-collectivism, a cultural dimension strongly associated with development (Hamamura, 2012) and known to implicate differences in generalized trust (Delhey et al., 2011; Yamagishi \& Yamagishi, 1994). Although this is a feasible possibility, in the current dataset individualism is uncorrelated with HDI $(r=-.04)$. For this reason, the effect we reported for HDI is independent of any possible effects associated with individualism.

\section{Conclusion}

Generalized trust appeared be an important predictor of health, psychological well-being, and a healthy lifestyle among older adults in non-Western countries. The findings from the current research also suggested the role of the countries' development differences in moderating this important association. 
Table 1. Descriptive Statistics.

\begin{tabular}{|c|c|c|c|c|c|c|}
\hline & China & Ghana & India & Mexico & Russia & South Africa \\
\hline HDI & .710 & .566 & .581 & .752 & .775 & .646 \\
\hline $\mathrm{N}$ & 13,367 & 4,724 & 7,150 & 2,315 & 3,933 & 3,840 \\
\hline$\%$ female & 53.1 & 50.3 & 49.4 & 60.5 & 64.6 & 57.4 \\
\hline Age & $63.16(9.44)$ & $64.21(10.72)$ & $61.86(9.03)$ & $68.39(9.53)$ & $65.07(10.18)$ & $62.73(9.70)$ \\
\hline$\%$ Generalized Trust & 89.11 & 62.00 & 55.51 & 48.19 & 29.56 & 21.43 \\
\hline Self-Rated Health & $3.14(.83)$ & $3.25(.83)$ & $3.07(.77)$ & $3.27(.73)$ & $2.83(.67)$ & $3.26(.82)$ \\
\hline Happiness & $3.58(.70)$ & $3.52(.86)$ & $3.46(.77)$ & $3.45(.78)$ & $3.33(.76)$ & $3.56(.87)$ \\
\hline Life Satisfaction & $3.65(.68)$ & $3.48(.83)$ & $3.69(.77)$ & $3.92(.64)$ & $3.45(.77)$ & $3.63(.82)$ \\
\hline Quality of Life & $3.60(.58)$ & $3.26(.64)$ & $3.43(.60)$ & $3.62(.52)$ & $3.39(.62)$ & $3.39(.61)$ \\
\hline \multicolumn{7}{|l|}{ Illness $(\%)$} \\
\hline Angina & 8.81 & 3.31 & 4.91 & 2.22 & 33.13 & 5.98 \\
\hline Arthritis & 22.03 & 13.09 & 17.90 & 12.27 & 35.20 & 23.25 \\
\hline Asthma & 2.46 & 3.73 & 6.94 & 3.26 & 3.40 & 4.51 \\
\hline Cataracts & 8.67 & 5.30 & 18.80 & 13.44 & 16.65 & 4.58 \\
\hline Diabetes & 6.54 & 3.89 & 7.29 & 20.33 & 9.02 & 9.84 \\
\hline Depression & .31 & 1.56 & 4.48 & 11.91 & 4.41 & 3.09 \\
\hline Hypertension & 27.57 & 13.64 & 17.52 & 37.77 & 56.53 & 30.63 \\
\hline Lung disease & 8.62 & .63 & 4.07 & 5.84 & 17.95 & 2.43 \\
\hline Stroke & 3.50 & 2.66 & 2.24 & 4.80 & 6.00 & 3.80 \\
\hline \multicolumn{7}{|l|}{ Health Behaviors } \\
\hline Dieting & $9.13(5.08)$ & $4.35(2.26)$ & $3.14(1.77)$ & $3.49(1.91)$ & $3.91(2.35)$ & $3.80(2.74)$ \\
\hline Physical Activity & $\begin{array}{c}2,280.37 \\
(1,666.95)\end{array}$ & $\begin{array}{c}2,254.58 \\
(1,129.98)\end{array}$ & $\begin{array}{c}1,983.20 \\
(1,541.84)\end{array}$ & $\begin{array}{c}2,341.10 \\
(1,742.00)\end{array}$ & $\begin{array}{c}2,349.83 \\
(1,482.91)\end{array}$ & $\begin{array}{c}1,867.35 \\
(1,712.11)\end{array}$ \\
\hline \multicolumn{7}{|c|}{ Health Compromising Behaviors } \\
\hline Drinking & $2.40(7.97)$ & $2.00(5.16)$ & $.63(3.82)$ & $2.46(13.16)$ & $1.94(4.87)$ & $1.83(7.98)$ \\
\hline Smoking & $\begin{array}{c}22,978.98 \\
(83,616.52)\end{array}$ & $\begin{array}{c}3,301.30 \\
(28,962.81)\end{array}$ & $\begin{array}{c}47,286.78 \\
(158,767.95)\end{array}$ & $\begin{array}{c}15,233.82 \\
(73,708.87)\end{array}$ & $\begin{array}{c}29,682.59 \\
(91,865.92)\end{array}$ & $\begin{array}{c}18,884.56 \\
(125,466.79)\end{array}$ \\
\hline Sedentary behavior & $\begin{array}{c}227.06 \\
(139.84)\end{array}$ & $\begin{array}{c}223.73 \\
(147.70)\end{array}$ & $\begin{array}{c}201.60 \\
(163.28)\end{array}$ & $\begin{array}{c}160.26 \\
(159.82)\end{array}$ & $\begin{array}{c}306.02 \\
(200.94)\end{array}$ & $\begin{array}{c}190.69 \\
(141.61)\end{array}$ \\
\hline
\end{tabular}


Table 2. Parameter Estimates in the Hierarchical Regression Model for Each Dependent Variable.

\begin{tabular}{|c|c|c|c|c|c|c|c|c|c|}
\hline & \multicolumn{5}{|c|}{ Step 1} & \multicolumn{2}{|c|}{ Step 2} & \multicolumn{2}{|c|}{ Step 3} \\
\hline & Gender & Age & Income & HDI & $\Delta \mathrm{R}^{2}$ & Trust & $\Delta \mathrm{R}^{2}$ & $\begin{array}{c}\text { Trust } \mathrm{x} \\
\text { HDI }\end{array}$ & $\Delta \mathrm{R}^{2}$ \\
\hline Self-Rated Health & $-.09 * *$ & $-.19 * *$ & $.14 * *$ & $-.04 * *$ & .073 & $.06 * *$ & .004 & $.03 * *$ & .001 \\
\hline Happiness & $-.04 * *$ & $-.03 * *$ & $.21 * *$ & -.003 & .049 & $.09 * *$ & .009 & $.05 * *$ & .001 \\
\hline Life Satisfaction & $-.04 * *$ & $-.06 * *$ & $.22 * *$ & $.03 * *$ & .058 & $.06 * *$ & .003 & $.03 * *$ & .0004 \\
\hline Quality of Life & $-.09 * *$ & $-.15 * *$ & $.28 * *$ & $.15 * *$ & .134 & $.11 * *$ & .012 & $.07 * *$ & .002 \\
\hline \multicolumn{10}{|l|}{ Illnesses } \\
\hline Angina & $\begin{array}{l}.30 * * \\
(1.35)\end{array}$ & $\begin{array}{l}.04 * * \\
(1.04)\end{array}$ & $\begin{array}{l}.07 * * \\
(1.07)\end{array}$ & $\begin{array}{c}9.93 * * \\
(20536.25)\end{array}$ & .115 & $\begin{array}{c}-.37 * * \\
(.69)\end{array}$ & .005 & $\begin{array}{c}-4.02 * * \\
(.02)\end{array}$ & .003 \\
\hline Arthritis & $\begin{array}{l}.51 * * \\
(1.66)\end{array}$ & $\begin{array}{l}.03 * * \\
(1.03)\end{array}$ & $\begin{array}{l}.04 * * \\
(1.04)\end{array}$ & $\begin{array}{l}2.91 * * \\
(18.36)\end{array}$ & .045 & $\begin{array}{c}-.14 * * \\
(.87)\end{array}$ & .002 & $\begin{array}{c}-2.13 * * \\
(.12)\end{array}$ & .001 \\
\hline Asthma & $-.10(.90)$ & $\begin{array}{l}.02 * * \\
(1.02)\end{array}$ & $\begin{array}{l}-.05 * \\
(.95)\end{array}$ & $-4.28 * *(.01)$ & .020 & $\begin{array}{c}-.19 * * \\
(.83)\end{array}$ & .001 & $\begin{array}{c}-2.84 * * \\
(.06)\end{array}$ & .002 \\
\hline Cataracts & $\begin{array}{l}.32 * * \\
(1.38)\end{array}$ & $\begin{array}{l}.07 * * \\
(1.07)\end{array}$ & $\begin{array}{l}.14^{* *} \\
(1.15)\end{array}$ & $-.59 * \quad(.55)$ & .099 & $\begin{array}{c}-.12 * * \\
(.89)\end{array}$ & .001 & $\begin{array}{c}-1.89 * * \\
(.15)\end{array}$ & .001 \\
\hline Diabetes & $\begin{array}{l}.28 * * \\
(1.32)\end{array}$ & $\begin{array}{l}.03 * * \\
(1.03)\end{array}$ & $\begin{array}{l}.25 * * \\
(1.28)\end{array}$ & $\begin{array}{l}2.93 * * \\
(18.69)\end{array}$ & .039 & $\begin{array}{c}-.32 * * \\
(.72)\end{array}$ & .004 & $.51(1.67)$ & .0001 \\
\hline Depression & $\begin{array}{l}.52 * * \\
(1.68)\end{array}$ & $\begin{array}{l}.01 * * \\
(1.01)\end{array}$ & $\begin{array}{l}.07 * * \\
(1.07)\end{array}$ & $.84 \quad(2.32)$ & .011 & $\begin{array}{c}-.73 * * \\
(.48)\end{array}$ & .016 & $\begin{array}{c}-5.43 * * \\
(.004)\end{array}$ & .004 \\
\hline Hypertension & $\begin{array}{l}.49 * * \\
(1.63)\end{array}$ & $\begin{array}{l}.04 * * \\
(1.04)\end{array}$ & $\begin{array}{l}.19 * * \\
(1.21)\end{array}$ & $\begin{array}{c}7.29 * * \\
(1462.46)\end{array}$ & .134 & $\begin{array}{c}-.34 * * \\
(.71)\end{array}$ & .006 & $\begin{array}{c}-1.00 * * \\
(.37)\end{array}$ & .0003 \\
\hline Lung disease & $\begin{array}{c}-.38 * * \\
(.68)\end{array}$ & $\begin{array}{l}.02 * * \\
(1.02)\end{array}$ & $-.02(.98)$ & $\begin{array}{c}10.24 * * \\
(27974.76)\end{array}$ & .086 & $\begin{array}{l}-.003 \\
(1.00)\end{array}$ & .000 & $\begin{array}{c}-2.71 * * \\
(.07)\end{array}$ & .001 \\
\hline Stroke & $\begin{array}{c}-.20 * * \\
(.82)\end{array}$ & $\begin{array}{l}.05^{* *} \\
(1.05)\end{array}$ & $\begin{array}{l}.08 * * \\
(1.09)\end{array}$ & $\begin{array}{l}3.72 * * \\
(41.27)\end{array}$ & .039 & $\begin{array}{c}-.22 * * \\
(.80)\end{array}$ & .001 & $.60(1.83)$ & .0001 \\
\hline \multicolumn{10}{|l|}{ Health Behaviors } \\
\hline Dieting & $-.05 * *$ & $-.09 * *$ & $.08 * *$ & $.29 * *$ & .098 & $.25 * *$ & .062 & $.23 * *$ & .025 \\
\hline Physical Activity & $-.12 * *$ & $-.12 * *$ & $-.07 * *$ & $.07 * *$ & .036 & -.02 & .0003 & $-.05 * *$ & .001 \\
\hline \multicolumn{10}{|c|}{ Health Compromising Behaviors } \\
\hline Drinking & $-.21 * *$ & $-.05 * *$ & $-.03 * *$ & $.08 * *$ & .050 & .01 & .00005 & $.03 * *$ & .0003 \\
\hline Smoking & $-.19 * *$ & $-.03 * *$ & $-.04 * *$ & -.01 & .037 & -.002 & .000 & $-.02 *$ & .0001 \\
\hline
\end{tabular}


Note. ${ }^{*} p<.05, * * p<.01$. Numbers are regression coefficients. For logistic regression analyses (in analyzing illnesses), numbers inside parentheses are odd ratios $[\operatorname{Exp}(B)]$ and Nagelkerke $R^{2}$ was used to assess the explained variance $\left(\Delta R^{2}\right)$. All $\Delta R^{2}$ were significant at $\mathrm{p}<.05$ except physical activity, drinking, and smoking in Step 2 and diabetes and stroke in Step 3. 
Table 3. Parameter Estimates of Generalized Trust in Countries High and Low in Development (one SD above or below mean of HDI)

\begin{tabular}{|c|c|c|c|}
\hline & & Low HDI & High HDI \\
\hline Self-Rated Health & $\beta$ & $.04 * *$ & $.09 * *$ \\
\hline Happiness & $\beta$ & $.06^{* *}$ & $.12 * *$ \\
\hline Life Satisfaction & $\beta$ & $.04 * *$ & $.08 * *$ \\
\hline Quality of Life & $\beta$ & $.06 * *$ & $.16^{* *}$ \\
\hline \multicolumn{4}{|l|}{ Illness } \\
\hline Angina & $b$ & $.10(1.11)$ & $-.51 * *(.60)$ \\
\hline Arthritis & $b$ & $.05(1.05)$ & $-.27 * *(.76)$ \\
\hline Asthma & $b$ & $-.02(.98)$ & $-.45 * *(.64)$ \\
\hline Cataracts & $b$ & $.03(1.04)$ & $-.25 * *(.78)$ \\
\hline Depression & $b$ & $-.28 * *(.76)$ & $-1.11 * *(.33)$ \\
\hline Hypertension & $b$ & $-.24 * *(.78)$ & $-.40 * *(.67)$ \\
\hline \multicolumn{4}{|l|}{ Health Behaviors } \\
\hline Dieting & $\beta$ & $.09 * *$ & $.40 * *$ \\
\hline \multicolumn{4}{|l|}{ Health Compromising } \\
\hline Sedentary behavior & $\beta$ & $.03 * *$ & $-.06 * *$ \\
\hline
\end{tabular}

Note. ${ }^{*} p<.05, * * p<.01$. Numbers are regression coefficients. For logistic regression analyses (in analyzing illness), numbers inside parentheses are odd ratios. 


\section{References}

Aiken, L. S., West, S. G., \& Reno, R. R. (1991). Multiple regression: Testing and interpreting interactions. Sage.

Andrews, Frank M. and John P. Robinson (1991). Measures of subjective well-being. In: John P. Robinson, Phillip R. Shaver and Lawrence S. Wrightsman (eds). Measures of Personality and Social Psychological Attitudes. San Diego, CA: Academic Press: 61-114.

Balliet, D., \& Van Lange, P. A. M. (2013). Trust, punishment, and cooperation across 18 societies: A meta-analysis. Perspectives on Psychological Science, 8(4), 363-379. doi: Doi $10.1177 / 1745691613488533$

Barefoot, J. C., Maynard, K. E., Beckham, J. C., Brummett, B. H., Hooker, K., \& Siegler, I. C. (1998). Trust, health, and longevity. Journal of Behavioral Medicine, 21(6), 517-526. doi: 10.1023/A:1018792528008

Benyamini, Y., \& Idler, E. L. (1999). Community studies reporting association between self-rated health and mortality. Research on Aging, 21(3), 393-401.

Bowlby, J. (1980). Attachment and loss (Vol. 3): Basic Book.

Cagney, K. and Wen, M. (2008) 'Social Capital and Aging-Related Outcomes', in Kawachi, I., Subramanian, S. V., and Kim, D. (eds.) Social Capital and Health. Springer, pp. 239-258.

Chan, D. K. C., Ivarsson, A., Stenling, A., Yang, X. S., Chatzisarantis, N. L. D., \& Hagger, M. S. (2015). Response-order effects in survey methods: A randomized controlled crossover study in the context of sport injury prevention. Journal of Sport and Exercise Psychology, 37(6), 666-673. doi:10.1123/jsep.2015-0045

Chan, D. K. C., Zhang, X., Fung, H. H., \& Hagger, M. S. (2016). Affect, affective variability and physical health: Results from a population-based investigation in China. International Journal of Behavioral Medicine, 23(4), 438-446. doi:10.1007/s12529-015-9510-2

Chan, D. K. C., Zhang, X., Fung, H. H., \& Hagger, M. S. (2015b). Does emotion and its daily fluctuation correlate with depression? A cross-cultural analysis among six developing 
countries. Journal of Epidemiology and Global Health, 5(1), 65-74.

doi:10.1016/j.jegh.2014.09.001

Cohen, J. (1992). A power primer. Psychological bulletin, 112(1), 155.

Cohen, S. (2004). Social relationships and health. American Psychologist,59(8), 676.

Craig, C. L., et al. (2003). International physical activity questionnaire: 12-country reliability and validity. Med Sci Sports Exerc 35: 1381-95.

Delhey, J., Newton, K., \& Welzel, C. (2011). How general is trust in "most people"? Solving the radius of trust problem. American Sociological Review,76(5), 786-807.

Erikson, E. (1963). Childhood and society. New York: Norton.

Everson, S. A., Kauhanen, J., Kaplan, G. A., Goldberg, D. E., Julkunen, J., Tuomilehto, J., et al. (1997). Hostility and Increased Risk of Mortality and Acute Myocardial Infarction: The Mediating Role of Behavioral Risk Factors. American Journal of Epidemiology, 146(2), 142-152.

Ferraro, K. F., Farmer, M. M., \& Wybraniec, J. A. (1997). Health trajectories: long-term dynamics among black and white adults. Journal of Health and Social Behavior, 38(1), 38-54.

Jamison, D. T., Breman, J. G., Measham, A. R., Alleyne, G., Claeson, M., Evans, D. B., ... \& Musgrove, P. (Eds.). (2006). Disease control priorities in developing countries. World Bank Publications.

Gilson, L. (2003). Trust and the development of health care as a social institution. Social Science and Medicine, 56(7), 1453-1468. doi:10.1016/S0277-9536(02)00142-9

Hagger, M. S., Chan, D. K. C., Protogerou, C., \& Chatzisarantis, N. L. D. (2016). Using metaanalytic path analysis to test theoretical predictions in health behavior: An illustration based on meta-analyses of the theory of planned behavior. Preventive Medicine, 89, 154-161. doi:10.1016/j.ypmed.2016.05.020 
Hagger, M. S., Chatzisarantis, N. L. D., Barkoukis, V., John, C. K., Hein, V., Pihu, M., . . Karsai, I. (2007). Cross-cultural generalizability of the theory of planned behavior among young people in a physical activity context. Journal of Sport and Exercise Psychology, 29(1), 2-20.

Hagger, M. S., Lonsdale, A. J., Hein, V., Koka, A., Lintunen, T., Pasi, H., . . Chatzisarantis, N. L. D. (2012). Predicting alcohol consumption and binge drinking in company employees: An application of planned behaviour and self-determination theories. British Journal of Health Psychology, 17(2), 379-407. doi:10.1111/j.2044-8287.2011.02043.x

Hamamura, T. (2011). Social class predicts generalized trust, but only in wealthy societies. Journal of Cross-Cultural Psychology, 43, 498-509.

Hamamura, T. (2012). Are cultures becoming individualistic? A cross-temporal comparison of individualism-collectivism in the United States and Japan. Personality and Social Psychology Review, 16(1), 3-24.

Hamamura, T., Li, L. M. W., Chan, D. K. C. (2016). Towards a systematic understanding of the association between generalized trust and physical and psychological health across societies. Social Indicator Research, advanced online publication. doi:10.1007/s11205-016-1428-9

Helliwell, J. F., \& Putnam, R. D. (2004). The social context of well-being. Philosophical transactions-royal society of London series B biological sciences, 1435-1446.

Houston, B. K., \& Vavak, C. R. (1991). Cynical hostility: developmental factors, psychosocial correlates, and health behaviors. Health Psychology, 10(1), 9.

Idler, E. L., \& Angel, R. J. (1990). Self-rated health and mortality in the NHANES-1 epidemiologic follow-up study. American Journal of Public Health, 80(4), 446-452.

Idler, E. L., \& Benyamini, Y. (1997). Self-rated health and mortality: A review of twenty-seven community studies. Journal of Health and Social Behavior, 38(1), 21-37.

Idler, E. L., \& Kasl, S. (1995). Self-ratings of health: Do they also predict change in functional ability? Journal of Gerontology, 50(6), S344-S353. 
Jette, M., Sidney, K., \& Blümchen, G. (1990). Metabolic equivalents (METS) in exercise testing, exercise prescription, and evaluation of functional capacity. Clinical Cardiology, 13(8), $555-565$.

Kaplan, G. A., Strawbridge, W. J., Camacho, T., \& Cohen, R. D. (1993). Factors associated with change in physical functioning in the elderly: A six-year prospective study. Journal of Aging and Health, 5(1), 40-53.

Keith, T. Z. (2005). Multiple regression and beyond. Boston: Pearson.

Li, T., \& Fung, H. H. (2013). Age differences in trust: An investigation across 38 countries. Journals of Gerontology Series B: Psychological Sciences and Social Sciences, 68, 347355. doi:10.1093/geronb/gbs072

Lim, S. S., Vos, T., \& Flaxman, A. D. (2013). A comparative risk assessment of burden of disease and injury attributable to 67 risk factors and risk factor clusters in 21 regions, 1990-2010: a systematic analysis for the Global Burden of Disease Study 2010 (vol 380, pg 2224, 2012). Lancet, 381(9874), 1276.

Lindström, M. (2004). Social capital, the miniaturisation of community and self-reported global and psychological health. Social Science \& Medicine, 59(3), 595-607.

Lindström, M. (2005). Social capital, the miniaturization of community and consumption of home made and smuggled liquor during the past year: A population-based study. European Journal of Public Health, 15(6), 593-600.

Lindström, M. (2008). Social capital and health-related behaviors. In I. Kawachi, S. V. Subramanian, \& D. Kim (Eds.), Social capital and health (pp. 215-238). NY: Sringer New York.

Lindström, M., Moghaddassi, M., Bolin, K., Lindgren, B., \& Merlo, J. (2003). Social participation, social capital and daily tobacco smoking: A population-based multilevel analysis in Malmö, Sweden. Scandinavian Journal of Public Health, 31(6), 444-450. 
Lindström, M., Moghaddassi, M., \& Merlo, J. (2003). Social capital and leisure time physical activity: a population based multilevel analysis in Malmö, Sweden. Journal of Epidemiology and Community Health, 57(1), 23. 23-28.

Maas, C. J., \& Hox, J. J. (2005). Sufficient sample sizes for multiple modeling. Methodology, 1, 8692. Doi:10.1027/1614-1881.1.3.86

Mohseni, M., \& Lindstrom, M. (2007). Social capital, trust in the health-care system and self-rated health: the role of access to health care in a population-based study. Social Science \& Medicine, 64(7), 1373-1383.

Nannestad, P. (2008). What have we learned about generalized trust, if anything? Annual Review of Political Science, 11, 413-436. doi: 10.1146/Annurev.Polisci.11.060606.135412

Nummela, O., Raivio, R., \& Uutela, A. (2012). Trust, self-rated health and mortality: A longitudinal study among ageing people in Southern Finland. Social Science and Medicine, 74(10), 1639-1643. doi: 10.1016/J.Socscimed.2012.02.010

Nummela, O., Sulander, T., Rahkonen, O., \& Uutela, A. (2009). The effect of trust and change in trust on self-rated health: A longitudinal study among aging people. Archives of Gerontology and Geriatrics, 49(3), 339-342. doi: 10.1016/J.Archger.2008.11.010

Mitchell, R., \& Popham, F. (2008). Effect of exposure to natural environment on health inequalities: an observational population study. The Lancet, 372(9650), 1655-1660.

Nieminen, T., Prättälä, R., Martelin, T., Härkänen, T., Hyyppä, M. T., Alanen, E., \& Koskinen, S. (2013). Social capital, health behaviours and health: a population-based associational study. BMC Public Health, 13(1), 613.

Poortinga, W. (2006). Social capital: An individual or collective resource for health? Social Science and Medicine, 62(2), 292-302.

Poulin, M. J., \& Haase, C. M. (2015). Growing to Trust Evidence That Trust Increases and Becomes More Important for Well-Being Across the Life Span. Social Psychological and Personality Science, 1948550615574301. 
Rogers, C. R. (1951). Client-centered therapy: Its current practice, implications, and theory. London: Constable.

Schneider, I. K., Konijn, E. A., Righetti, F., \& Rusbult, C. E. (2011). A healthy dose of trust: The relationship between interpersonal trust and health. Personal Relationships, 18(4), 668-676. doi: $10.1111 / \mathrm{J} .1475-6811.2010 .01338 . \mathrm{X}$

Schmidt, S., Mühlan, H., \& Power, M. (2006). The EUROHIS-QOL 8-item index: psychometric results of a cross-cultural field study. The European Journal of Public Health, 16(4), 420428.

Smith, T. W. (1992). Hostility and health: current status of a psychosomatic hypothesis. Health psychology, 11(3), 139.

World Health Organization. (2008). The global burden of disease : 2004 update. Geneva: WHO Press.

World Health Organization. (2015). World health statistics 2015. Geneva: WHO Press.

Yamagishi, T., \& Yamagishi, M. (1994). Trust and commitment in the United States and Japan. Motivation and Emotion, 18(2), 129-166. 